\title{
Comparing Family Drawing Test Indices and Behavioral Problems between Iranian and Afghan Emigrant Children, Isfahan Province,
}

\section{Iran}

\author{
Mohamad Davari ${ }^{1}$ and Sayed Abbas Haghayegh ${ }^{2,{ }^{*}}$ \\ ${ }^{1}$ M.Sc of Clinical Psychology, Najafabad Branch, Islamic Azad University, Najafabad, Iran \\ ${ }^{2}$ Department of Psychology, Najafabad Branch, Islamic Azad University, Najafabad, Iran \\ "Corresponding author: Department of Psychology, Najafabad Branch, Islamic Azad University, Najafabad, Iran. Tel:+98-3142293030, Fax:+98-3142292197, Email: \\ abbas_haghayegh@yahoo.com
}

Received 2018 April 08; Revised 2019 May 06; Accepted 2020 February 23.

\begin{abstract}
Background: Immigration can be accompanied by many psychological outcomes for emigrant families.

Objectives: The present study aimed to compare family drawing test indices and behavioral problems among Iranian and Afghan emigrant children.

Methods: The research design was a comparative and cross-sectional study. We included 550 Iranian and Afghan students aged 7 11 years in Isfahan Province from April to June 2017. Achenbach Behavioral Problem questionnaire (2001) was sent to their mothers for filling, and Drawing Family Test was conducted. After reducing the number of dropout students, the final sample reached 282 students (including 174 Iranian students and 108 Afghan immigrants)., SPSS-23 software and chi-square tests as well as multivariate analysis of variance were used for analyzing data.

Results: The results of the chi-square test showed that there was a significant difference in some of the drawing indices, including size, rhythm, location of drawing, valuation, removal of person, and distances between two groups of Iranian students and Afghan migrants $(\mathrm{P}<0.05)$. Also, the results of multivariate analysis of variance indicated that there was a significant difference among mean scores of behavioral problems and dimensions of somatization, thinking problems and anti-social problems in the two groups $(\mathrm{P}<0.05)$. There was no significant difference in other variables.

Conclusions: According to the results, the children of the Afghan refugee group have more both behavioral problems and drawing indices than the Iranian group.
\end{abstract}

Keywords: Behavioral Problems, Children, Emigration, Family Drawing Test

\section{Background}

The outcomes of immigration on behavioral problems have shown a risk perspective. This risk perspective focuses on the psychological problems of migration and the need to adapt to a new cultural environment (1). learning language, occupational, and social stressors set the stage for intergenerational conflict and stress in these families (2). These perspectives also emphasize that migrant families are frequently confronted with discrimination (3) which may negatively affect psychological status (4).

Children in migrant families are thought at increased risk for child maltreatment due to struggles related to difficult economic status; adverse interactions with law enforcement, and poor supportive network (5-7). In the case of comparison between groups, according to their risk profile, children in immigrant families significantly differ from children with US-born parents in unpleasant maltreatment and relational experiences $(6,8)$. Migrant children confronted with challenges of living in a new social and cultural environment in cities, although their family structure and values may not have changed (9). Almost $20 \%$ of emigrant parents left their children in their hometown when they were less than one year old (10). In addition, these children's long-term separation from parent(s), as well as unhealthy family and emotional caring, greatly impacts their life quality and their physical and psychological function as they grow-up $(10,11)$. Due to emigrant parents' high work hours and relatively low level of education, emigrant parents often lack the time and skills to supervise their children's educational status; this inadequate parent-child communication makes emigrant chil- 
dren more likely to have negative feelings, especially loneliness than urban children (12). interethnic and intercultural challenges are an urgent object of the scientific and practical research, today (13).

One of the commonly used methods for evaluating the psychological status of children, has been an analysis of their drawings. Children's drawings can give clues about their previous and current lives. The child's personality characteristics can be revealed through their drawings (14, 15). Clinicians and researchers believe that analytic interpretation of drawing indexes reveals negative affects (16) and traits, giving insight about who a person is (17). Drawing can fulfill different functions of children such as helping them recognize ideas about their selves, world and enable them to create visual representations of their thoughts and feelings (18). Drawing skills emerge during the second year of life and grow significantly through childhood (19-21). Drawings have also been used to identify attachment patterns in non-abused children $(22,23)$. Despite some criticism about the validity of drawings as a projective test, practitioners with different theoretical approaches consider drawings as instruments that allow the child to express his/her negative affects (21).

Children with behavioral problems have inappropriate severe and inevitable reactions which are not individually and socially acceptable (24). Childhood behavioral problems are usually classified in two broad areas: internalizing and externalizing disorders. Externalizing disorders are identified with behaviors such as aggression, disobedience, hyperactivity, and impulsiveness; while, internalizing disorders are identified with experiences and behaviors such as depression, social isolation and anxiety (25). Children with behavioral problems are prone to depression (26) and the risk of having high-risk behaviors is more likely to threaten their health (27).

Afghans' immigration has been the greatest movement in the last three decades of modern world history and more than $96 \%$ of it has been directed toward Iran and Pakistan $(28,29)$. Given the history of Afghans' immigration to Iran, which has been started seriously and extensively from 1979 (30), it can be said that Afghans have been interacting with Iranians at least for 36 years, in the "immigrant" position. During this time, their relationship has always been affected as an "alien" minority with the host community by two facts: on the one hand, it is influenced by the fact that the host community has not accepted them as "Iranians" and on the other hand, it is affected by their own characteristics as marginal people (28). Despite the large number of Afghan refugees in Iran, few researches have been carried out on the emigrant children's problems.

\section{Objectives}

This research aimed to compare the family drawing test indices and behavioral problems in both concrete (Achenbach questionnaire) and projective (family draw test) measures among Iranian and Afghan emigrant children

\section{Methods}

\subsection{Participants}

The research design was a comparative and crosssectional study. We included 550 students from the primary school of Isfahan and Najafabad from April 20 to June 10, 2017. According to statistical methods-analysis of variances and chi square-and 20 dependent variables, a sample size between 500 - 600 participants was required to achieve a high statistical power. First, Achenbach Behavioral Problem questionnaire was administered to students' mothers and then, the drawing family test was performed. Inclusion criteria was ages between 7 and 11 years old; informed consent of their parents and exclusion criteria consisted of failure to answer the questions of the Achenbach Behavioral questionnaire, as well as withdrawal or dissatisfaction with continuing the family drawing test. Finally, 282 students were included. Among them, 174 were Iranian while 108 were Afghan students.

\subsection{Instruments}

\subsubsection{Draw A Family Test}

This test was initially proposed by Dapple and Wolf but it was fully elaborated later as draw a family test (DAF) by Hals (1951). DAF Test reflects individual's relationships and their family needs in addition to their characteristics. This test is useful for children or adolescents who talk difficultly about their feelings or family (31). Family Drawing test (DAF) is a method of projection based on the psychoanalysis of stating the issues and family conflicts which has a wide application in diagnostic and psychotherapy activities of children, because on the one hand, it distinguishes sustainable and unsustainable transformations of child's personality. On the other hand, it shows the transformation that is the result of therapy (32). Different results have been reported considering the reliability and validity of the Kremen test and interview questions. Reliability coefficients of scoring was positioned by various value finders ranging from 0.87 to 0.95 but retest reliability coefficients have been reported to be lower. Moreover, the Cranbach alpha value is reported to be 0.71 (32). The Cronbach's alpha of the Iranian version of this test has been reported 0.82 and the face validity has been approved (33). 
Parental version of Achenbach list of child behavioral problems was built in 1991 by Achenbach in which Children and adolescents' problems are evaluated in eight aspects including anxiety/depression, isolation/depression, physical complaints, social problems, thinking problems, attention problems, ignoring rules and aggressive behavior. This questionnaire measures emotional-behavioral problems as well as the educational and social competencies and capabilities of children aged between 6 to18 from parental perspective and it takes 20 - 25 minutes to be filled The behavioral list of children is a tool which is also completed by one parent or another person who is familiar with the child's competencies and behavioral problems. These tools can be performed in forms of both self-report and interview. The overall coefficients of the test validity were reported 0.97 using Cronbach Alpha while it was reported 0.94 using a retest reliability. Content validity (selection of the questions' logic and using first-class analysis of questions), the validity of criterion (using a psychiatric interview with a child as well as correlation with the CSI4 scale) and structural validity (internal relations of scales and group differentiation) of these forms have been reported to be desirable. The temporal stability of scales has been investigated using the test-retest method with a time interval of 8 - 5 weeks in which the range of time stability coefficients was obtained from 0.32 to 0.67 . The agreement between respondents has also been reviewed in which the range of these coefficients varied from 0.09 to 0.67 . Generally, the Iranian version of this test has acceptable validity and reliability. The Cronbach's alpha coefficient of subscales has been reported between 0.63 and 0.95 (34).

\subsection{Procedure}

At first, Coordination was done with the Department of Education in Isfahan. Then, the education office of the 3rd district of Isfahan, which has many foreign immigrants as well as the city of Najafabad, was selected. After identifying the schools in which the test should be run; school administrators were informed and the date and time of attending were determined. The primary sample for conducting the test included 550 students that 268 of them were removed from research because of the following reasons; lack of participation in a drawing test or drawing things other than painting a family; not having a name or mismatching the student's name; having a higher or lower age than the age range defined in the research. In each class, the necessary explanations were presented about drawing and students were asked to draw their family. They were given 20 - 30 minutes to complete their drawing. The following questions were asked after finishing the drawing: Have you drawn all family members; if a person is removed, who is that person?; what is the cause of their removal? How was the order of drawing people? also, according to the drawing possible ambiguities and points which were necessary to be specified, other questions were asked of them. The form of drawing test indicators was completed and graded for each student individually according to their drawings and an interview was done. At the end, scores were obtained and entered the statistical software to be analyzed.

\subsection{Ethical Considerations}

This article has been extracted from the master's thesis and approved at research deputy. The participants were fully aware of the study's objectives and willing to participate in it and were allowed to leave the project at any time.

\subsection{Data Analysis}

Data were analyzed using SPSS-23 software. The mean and standard deviation of demographic characteristics as well as the frequency and percentage of drawing indicators were used in the descriptive section and in the final analysis, chi-square test (considering the variables being categorized) was used to compare the test scores of the drawing and analysis of variance was implemented for comparison of behavioral problems (after examining the assumptions of normalization with Kolmogorov-Smirnov test and equality of variances with Levene test).

\section{Results}

The mean age and standard deviation for the Iranian group were equal to 9.3 (0.97) while they were obtained 9.65 (1.33) for the Afghan refugee group. Other demographic characteristics of research samples are presented in Table 1. Moreover, descriptive findings and final analysis are shown in Tables 2 and 3.

The results in Table 2 indicate that the difference between two groups of Iranian and emigrant students in the indicators of size, rhythm, drawing location, valuation, deletion of person and distance is significant $(\mathrm{P}<0.05)$. Other indicators were not significantly different. After testing normal distribution by Kolmogorov-Smirnov test and equality of variances with the Levene test, the behavioral problems were analyzed by analysis of variances. The results presented in Table 3.

Based on the findings in Table 3, the difference between mean scores in overall behavioral problems, dimensions of somatization, problems of thinking and antisocial problem was significant in two groups $(\mathrm{P}<0.05)$ but no significant difference was observed between the scores of depression-anxiety, depression-depression, social problems, attention and aggression of the two groups. 


\begin{tabular}{|c|c|c|}
\hline Groups & Iranian & Emigrant \\
\hline \multicolumn{3}{|l|}{ Gender } \\
\hline Boy & $1(0.6)$ & $46(42.6)$ \\
\hline Girl & $173(99.4)$ & $62(57.4)$ \\
\hline \multicolumn{3}{|l|}{ Grade } \\
\hline First & - & $5(4.6)$ \\
\hline Second & $52(29.9)$ & $29(26.9)$ \\
\hline Third & $77(44.3)$ & $62(57.4)$ \\
\hline Forth & $45(25.9)$ & $12(11.1)$ \\
\hline \multicolumn{3}{|l|}{ Status of father's job } \\
\hline Employed & $170(97.7)$ & $102(94.4)$ \\
\hline Unemployed & $4(2.3)$ & $6(5.6)$ \\
\hline \multicolumn{3}{|l|}{ Status of mother's job } \\
\hline Employed & $17(9.8)$ & $12(11.1)$ \\
\hline Unemployed & $157(90.2)$ & $96(88.9)$ \\
\hline \multicolumn{3}{|l|}{ Father's education level } \\
\hline Illiterate & $6(3.4)$ & $53(49.1)$ \\
\hline Diploma & $153(87.9)$ & $54(50)$ \\
\hline $\begin{array}{l}\text { Having university } \\
\text { degree }\end{array}$ & $15(8.6)$ & $1(0.9)$ \\
\hline \multicolumn{3}{|l|}{ Mother's education level } \\
\hline Illiterate & $10(5.7)$ & $66(61.1)$ \\
\hline Diploma & $144(82.8)$ & $41(38)$ \\
\hline $\begin{array}{l}\text { Having university } \\
\text { degree }\end{array}$ & $20(11.5)$ & 1() \\
\hline \multicolumn{3}{|l|}{ Birth order } \\
\hline First & $52(29.9)$ & $23(21.3)$ \\
\hline Middle & $31(17.8)$ & $46(42.6)$ \\
\hline Last & $1(40.2)$ & $46(35.2)$ \\
\hline Single child & $173(12.1)$ & $62(0.9)$ \\
\hline
\end{tabular}

${ }^{\mathrm{a}}$ Values are expressed as No. (\%).

\section{Discussion}

This research aimed to compare family drawing test and behavioral problems between Iranian and emigrant primary school children. The obtained results are discussed in the following.

There is a significant difference in the frequency of family drawing test indices in two groups of Iranian and non-Iranian primary school children. It was indicated that the drawing indices of Afghan refugee children are different from Iranian kids. That is, the abundance of some of the DAF test indices such as drawing size, rhythm of drawing, drawing location, valuation, removing a person and having distance with family members in emigrant children is more than Iranian children (19). Indicator of drawing size had three large, medium and small items; although the size of drawing of most Iranian and emigrant children was their average, the size of the drawing in about $26 \%$ of emigrant students was small. When the size of the drawing is small, It can mean depression, shyness and fear. On the contrary, when the child draws his painting to a large scale which exceeds the limit of paper, it can be a sign of convenience in self-expression (21). Indulgence in such feelings represents imbalance. Index of drawing rhythm included 2 states of with and without interruption; about 17 percent of emigrant students in this index draw their paintings with interruptions. It is often observed that a child repeats lines of symmetry in drawing a person or from person to another. This tendency to repeat the rhythm, which is sometimes followed up to real stereotypic behavior, is contrary to the free drawing that is the function of imagination and it means exactly that the subject has lost part of their temperament and normal state or lives under the influence of the imposed rules which can be related to strict restrictions and rules that the parents of Afghan children are likely to consider for the country in another country (19). The area of the page that is occupied by the painting can have a graphical meaning (21). In fact, along with children who use the entire page, there are subjects who limit their drawing to a small part of the page. In this index, about $29 \%$ of emigrant children had drawn their paintings at the bottom of the page which is more seen in depressed children. Depressed and incapable subjects who just draw at the bottom of the page, may be the children who are forbidden to have any sort of mutation toward the higher position and any kind of imagination (due to external or internal censorship). In the valuation index, emigrant children have acquired higher scores compared with Iranian children, in removing a person and also distance with family members. When a participant does not draw himself, it can be said that he does not feel comfortable in his current position in terms of age and sex. In addition, he wants to be someone else. Actually, it cannot be imagined that a child can remove himself from his family system. Therefore, it should be accepted that he has drawn himself in the form of someone else except in special cases who wants to occupy his place (20). In this case, it must be discovered that who his desire is matching. Also the matter that the child assumes themselves to be removed from the family means that may have difficulty to establish relationships with other members of the family. These results can be explained with feelings of rejection and being different which may have been created in the interactions of emigrant children with Iranian kids and can cause negative self-esteem. 


\begin{tabular}{|c|c|c|c|c|}
\hline \multirow{2}{*}{ Variable } & \multicolumn{2}{|c|}{ Values } & \multirow{2}{*}{$\mathbf{F}$} & \multirow{2}{*}{ P Value $^{b}$} \\
\hline & Iranian & Afghan & & \\
\hline Depression-anxiety & $7.35 \pm 4.73$ & $7.57 \pm 4.72$ & 0.157 & 0.693 \\
\hline Depression-isolation & $3.22 \pm 2.66$ & $3.47 \pm 2.54$ & 0.626 & 0.43 \\
\hline Somatization & $2.7 \pm 2.9$ & $3.78 \pm 3.45$ & 8.057 & 0.005 \\
\hline Social problems & $4.31 \pm 3.13$ & $4.34 \pm 3.29$ & 0.004 & 0.951 \\
\hline Thinking problems & $2.61 \pm 2.74$ & $3.77 \pm 2.99$ & 11.174 & 0.001 \\
\hline Attention problems & $3.9 \pm 3.22$ & $4.54 \pm 3.14$ & 2.658 & 0.104 \\
\hline Anti-social problems & $2.39 \pm 1.97$ & $2.97 \pm 2.49$ & 4.619 & 0.032 \\
\hline Aggression & $7.39 \pm 5.57$ & $8.74 \pm 5.85$ & 3.589 & 0.059 \\
\hline
\end{tabular}

${ }^{\mathrm{a}}$ Values are expressed as mean $\pm \mathrm{SD}$.

${ }^{\mathrm{b}}$ Significant level $<0.05$.

The results of this study indicate that immigrant elementary school students gained a higher score than Iranian students in some behavioral problems like somatization, problems of thinking, anti-social harms as well as the total score of behavioral problems. According to the findings, the prevalence of some behavioral problems (subscales of checklist of Achenbach child behavioral problems) among emigrant children is higher than Iranian children. An interesting point in the results is that both somatization problems (as one of the intrinsic problems) and also anti-social complications (as one of the exogenous problems) is higher in Afghan children (Table 3) which indicates that negative coping strategies to overcome or existing problems are different and it is not merely show itself in the form of internalizing behaviors. This should be considered by countries which accept the immigrants. Perhaps the cultural adjustment level of families with the new society (especially given the religious difference), social rejection of immigrants (which could be due to the negative stereotypic impressions of Iranian citizens), separation from relatives (which can make feeling of loneliness and being different) (35) can be known as reasons of higher levels of behavioral problems in the studied population. Aggression is one of the most common externalizing behavior problems in childhood and adolescence. Many environmental factors in the life of Afghan children such as feeling of rejection in the interpersonal relationships, family problems, unwanted behavioral and emotional misconducts in the family environment, and patterning of aggression (25) in peer groups can explain the higher scores of this group compared to the Iranian students. Of course, it should be noted that this behavior is a kind of defensive response that helps the child and adolescent to reduce the emotional threats in the family environment and relation- ships with peers (25). Based on the results, the somatization subscale scores of the behavioral disorders in Afghan students are significantly higher than those of Iranian students. The interesting point in the results is that the aggression scores as the externalized behavior disorders are higher in these children, as well as the subscales scores of somatization as an internalized behavior disorder. An explanation can be that these children act on the basis of the learned pattern of emotional expression, due to a basic and underlying feeling of anxiety resulting from leaving the home country and problems of adaptation to the new environment (26). In the sense that if family and environmental conditions give these children the possibility of aggression, they will defend from their anxiety and worry, and if they are not able of the self-externalization through aggression, they will show their physical symptoms.

\subsection{Limitations and Advantages}

One of the limitations could be related to the lack of a complementary interview after testing, that could alter the interpretation of drawing indexes. It is recommended that other behavioral problems such as unfavorable behavioral patterns and educational problems which were not investigated in this study, be considered in future research., further researches need more attention to psychological problems of Afghan emigrant children in Iran. Despite the large number of Afghan refugees in Iran, few researches have been carried out on the problems of the children of the emigrants.

\subsection{Conclusions}

It seems that Afghan emigrant children in Iran suffer from psychological problems which are shown in two levels, including projection indicators (family drawing test) 
and objective (behavioral problems of Achenbach questionnaire). Probably, environmental factors such as insufficient attention of schools to the expectations and special emotional needs of these children and the factors inside family-like negative stereotypic attitudes about communication with Iranian children and feeling lonely have a role in the mentioned problems in both groups which indicates the need for special programs for more emotional affinity among families of Afghan children and families of Iranian kids and administrative staff of schools.

\section{Acknowledgments}

We appreciate all participants in this study and those who helped us in conducting this research. We also appreciate of education department of Isfahan province for collaboration to sampling. This article has been extracted from the Master's Thesis and approved at research deputy.

\section{Footnotes}

Authors' Contribution: Mohamad Davari conducted the sampling, performed the intervention, and collected the data. Sayed Abbas Haghayegh designed the research, performed the statistics analysis, drafted, and revised the manuscript.

Conflict of Interests: No conflict of interest of authors.

Funding/Support: No funding.

Informed Consent: The participants were to be fully aware of the study's objectives and willing to participate in it and were allowed to leave the project at any time.

\section{References}

1. Guarnaccia PJ, Lopez S. The mental health and adjustment of immigrant and refugee children. Child Adolesc Psychiatr Clin N Am. 1998;7(3):537-53. viii-ix. [PubMed: 9894054].

2. Le TN, Stockdale G. Acculturative dissonance, ethnic identity, and youth violence. Cultur Divers Ethnic Minor Psychol. 2008;14(1):1-9. doi: 10.1037/1099-9809.14.1.1. [PubMed: 18229995].

3. Noh S, Kaspar V. Perceived discrimination and depression: moderating effects of coping, acculturation, and ethnic support. Am J Public Health. 2003;93(2):232-8. doi: 10.2105/ajph.93.2.232. [PubMed: 12554575]. [PubMed Central: PMC1447722].

4. Pascoe EA, Smart Richman L. Perceived discrimination and health: A meta-analytic review. Psychol Bull. 2009;135(4):531-54. doi: 10.1037/a0016059. [PubMed: 19586161]. [PubMed Central: PMC2747726].

5. Androff DK, Ayon C, Becerra D, Gurrola M. US immigration policy and immigrant children's well-being: The impact of policy shifts. J Soc Soc Welfare. 2011;38:77.

6. Dettlaff AJ, Johnson MA. Child maltreatment dynamics among immigrant and U.S. born Latino children: Findings from the National Survey of Child and Adolescent Well-being (NSCAW). Child Youth Serv Rev. 2011;33(6):936-44. doi:10.1016/j.childyouth.2010.12.017.
7. Finno M, de Haymes MV, Mindell R. Risk of affective disorders in the migration and acculturation experience of Mexican migrants. Migr. 2006.

8. Dettlaff AJ, Earner I. Children of immigrants in the child welfare system: Characteristics, risk, and maltreatment.Fam Soc. 2018;93(4):295303. doi: 10.1606/1044-3894.4240.

9. Fan XH, Fang XY, Liu QX, Liu YOBNU. Social adaptation comparison of migrant children, left-behind children, and ordinary children. J Beijing. 2009;251(5):33-40.

10. All-China Women's Federation. The research report of left-behind children and migrant children in rural China. Southwest China Normal University Press Chongqing; 2013.

11. Su S, Li X, Lin D, Xu X, Zhu M. Psychological adjustment among leftbehind children in rural China: the role of parental migration and parent-child communication. Child Care Health Dev. 2013;39(2):162-70. doi: 10.1111/j.1365-2214.2012.01400.x. [PubMed: 22708901].

12. Guo L, Yao Y, Yang B. Adaptation of migrant children to the city: A case study at a migrant children school in Beijing. Youth Study. 2005;3:22-

13. brdov M, Bauer E. Study results of the russian and german schoolchildren's psychological features and social and psychological adaptation features. Proced Soc Behav Sci. 2017;237:1105-11. doi 10.1016/j.sbspro.2017.02.163.

14. Oguz V. The factors influencing childrens' drawings. Proced Soc Behav Sci. 2010;2(2):3003-7. doi: 10.1016/j.sbspro.2010.03.455.

15. Artut K. Art education theories and methods. 5th ed. Ankara: Ani Publishing; 2006.

16. Freilich $\mathrm{R}$, Shechtman $\mathrm{Z}$. The contribution of art therapy to the social, emotional, and academic adjustment of children with learning disabilities. Arts Psychother. 2010;37(2):97-105. doi: 10.1016/j.aip.2010.02.003.

17. Malchiodi CA. Understanding children's drawings. London: Jessica Kingsley; 1998.

18. Brooks M. Drawing, visualisation and young children's exploration of "big ideas". Int J Sci Educ. 2009;31(3):319-41. doi 10.1080/09500690802595771.

19. Braswell G, Rosengren K. The interaction of biomedical and cognitive constraints in the production of children-s drawings. New York: Cambridge University Press; 2008.

20. Finzi R, Cohen O, Sapir Y, Weizman A. Attachment styles in maltreated children: A comparative study. Child Psychiatry Hum Dev. 2000;31(2):113-28. doi:10.1023/a:1001944509409. [PubMed:11089300].

21. Piperno F, Di Biasi S, Levi G. Evaluation of family drawings of physically and sexually abused children. Eur Child Adolesc Psychiatry. 2007;16(6):389-97. doi: 10.1007/s00787-007-0611-6. [PubMed: 17401609].

22. Kaiser DH, Deaver S. Assessing attachment with the bird's nest drawing: A review of the research. Art Ther. 2009;26(1):26-33. doi 10.1080/07421656.2009.10129312.

23. Sheller S. Understanding insecure attachment: A study using children's bird nest imagery. Art Ther. 2007;24(3):119-27. doi: 10.1080/07421656.2007.10129427.

24. Aghaee A. [The effectiveness of mothers' behavioral training on emotional and behavioral disorders of preschool children deprived of father]. University of Isfahan; 2001. Persian.

25. Arabi S, Danesh E, Kakavand AR, Saliminia AR, Amirghafari M. Efficacy of parent management training on reducing symptoms of external disturbances in children with attention deficit/hyperactivity. Alborz Univ Med J. 2013;2(3):139-46. doi: 10.18869/acadpub.aums.2.3.139.

26. Roza SJ, Hofstra MB, van der Ende J, Verhulst FC. Stable prediction of mood and anxiety disorders based on behavioral and emotional problems in childhood: A 14-year follow-up during childhood, adolescence, and young adulthood. Am J Psychiatry. 2003;160(12):2116-21. doi:10.1176/appi.ajp.160.12.2116. [PubMed:14638580]. 
27. Fanti KA, Henrich CC. Trajectories of pure and co-occurring internalizing and externalizing problems from age 2 to age 12: Findings from the National Institute of Child Health and Human Development Study of Early Child Care. Dev Psychol. 2010;46(5):1159-75. doi: 10.1037/a0020659. [PubMed: 20822230].

28. Abbasi-Shavazi MJ, Sadeghi R. Socio-cultural adaptation of secondgeneration Afghans in Iran. Int Migr. 2015;53(6):89-110. doi: 10.1111/imig.12148.

29. Adelkhah F, Olszewska Z. The Iranian Afghans. Iran Stud. 2007;40(2):137-65. doi: 10.1080/00210860701269519.

30. Hugo G, Abbasi-Shavazi MJ, Sadeghi R. Refugee movement and development - Afghan refugees in Iran. Migr Develop. 2012;1(2):261-79. doi: 10.1080/21632324.2012.749741.
31. Kaplan N, Main M. Instructions for the classification of children's family drawings in terms of representation of attachment. Berkeley: University of California; 1986.

32. Groth-Marnat G, Baker S. Digit Span as a measure of everyday attention: A study of ecological validity. Percept Mot Skills. 2003;97(3 Pt 2):1209-18. doi: 10.2466/pms.2003.97.3f.1209. [PubMed: 15002866].

33. Hashemi N, Fadavi S. [Analysis of children's drawings]. J Anal Res Negareh. 2009;12:106-17. Persian.

34. Minaee A. [Manual of school age forms in assessment system based on the experience of achenbach (ASEBA)]. Tehran: Exceptional Children's Research Center; 2005. Persian.

35. Tribe R. Mental health of refugees and asylum-seekers. Adv Psychiatr Treat. 2018;8(4):240-7. doi:10.1192/apt.8.4.240. 
Table 2. Frequency and Percentage of Family Drawing Test Indicators in Two Groups ${ }^{\mathrm{a}}$

\begin{tabular}{|c|c|c|c|c|c|}
\hline Groups & Iranian & Emigrants & $\begin{array}{l}\text { Chi-Square } \\
\text { Value }\end{array}$ & df & PValue $^{b}$ \\
\hline Size & & & 915.8 & 2 & 0.012 \\
\hline Small & $21(12.1)$ & $28(25.9)$ & & & \\
\hline Medium & $149(85.6)$ & $78(72.2)$ & & & \\
\hline Large & $4(2.3)$ & $2(1.9)$ & & & \\
\hline Rhythm & & & 4.923 & 1 & 0.027 \\
\hline $\begin{array}{l}\text { Without } \\
\text { interruption }\end{array}$ & $160(92)$ & $90(83.3)$ & & & \\
\hline With interruption & $14(8)$ & $18(16.7)$ & & & \\
\hline Place of drawing & & & 24.887 & 7 & 0.001 \\
\hline Down & $23(13.2)$ & $31(28.7)$ & & & \\
\hline Up & $7(4)$ & $6(5.6)$ & & & \\
\hline Left & $12(6.9)$ & $6(5.6)$ & & & \\
\hline Right & $4(2.3)$ & $1(0.9)$ & & & \\
\hline Down and left & $7(4)$ & $8(7.4)$ & & & \\
\hline Down and right & $0(0)$ & $5(4.6)$ & & & \\
\hline Up and right & $1(0.6)$ & $0(0)$ & & & \\
\hline Middle & $120(69)$ & $51(47.2)$ & & & \\
\hline $\begin{array}{l}\text { The thickness of the } \\
\text { lines }\end{array}$ & & & 0.762 & 2 & 0.683 \\
\hline Thick & $37(21.3)$ & $27(25)$ & & & \\
\hline Normal & $123(70.7)$ & $71(65.7)$ & & & \\
\hline Thin & $14(8)$ & $10(9.3)$ & & & \\
\hline Valuation person & & & 17.887 & 6 & 0.007 \\
\hline Without valuation & $44(25.3)$ & $24(22.2)$ & & & \\
\hline Self-valuation & $18(10.3)$ & $16(14.8)$ & & & \\
\hline Mother valuation & $58(33.3)$ & $19(17.6)$ & & & \\
\hline Father valuation & $25(14.4)$ & $29(26.9)$ & & & \\
\hline Brother valuation & $12(6.9)$ & $13(12)$ & & & \\
\hline Sister valuation & $17(9.8)$ & $6(6.5)$ & & & \\
\hline $\begin{array}{l}\text { valuation of } \\
\text { others }\end{array}$ & $0(0)$ & $1(0.9)$ & & & \\
\hline Removal & & & 31.613 & 5 & 0.001 \\
\hline Without removal & $134(77)$ & $50(46.3)$ & & & \\
\hline Self-removal & $6(3.4)$ & $10(9.3)$ & & & \\
\hline Removing mother & $0(0)$ & $3(2.8)$ & & & \\
\hline Removing father & $5(2.9)$ & $3(2.8)$ & & & \\
\hline $\begin{array}{l}\text { Removing } \\
\text { brother }\end{array}$ & $12(6.9)$ & $19(17.6)$ & & & \\
\hline Removing sister & $17(9.8)$ & $23(21.3)$ & & & \\
\hline $\begin{array}{l}\text { Distance with family } \\
\text { members }\end{array}$ & & & 11.862 & 4 & 0.018 \\
\hline Without distance & $130(74.7)$ & $68(63)$ & & & \\
\hline $\begin{array}{l}\text { Distance with } \\
\text { mother }\end{array}$ & $19(10.9)$ & $19(17.6)$ & & & \\
\hline $\begin{array}{l}\text { Distance with } \\
\text { father }\end{array}$ & $16(9.2)$ & $20(18.5)$ & & & \\
\hline $\begin{array}{l}\text { Distance with } \\
\text { brother }\end{array}$ & $4(2.3)$ & $1(0.9)$ & & & \\
\hline $\begin{array}{l}\text { Distance with } \\
\text { sister }\end{array}$ & $5(2.9)$ & $0(0)$ & & & \\
\hline Shadow & & & 3.854 & 2 & 0.146 \\
\hline Without shadow & $173(99.4)$ & $0(0)$ & & & \\
\hline
\end{tabular}




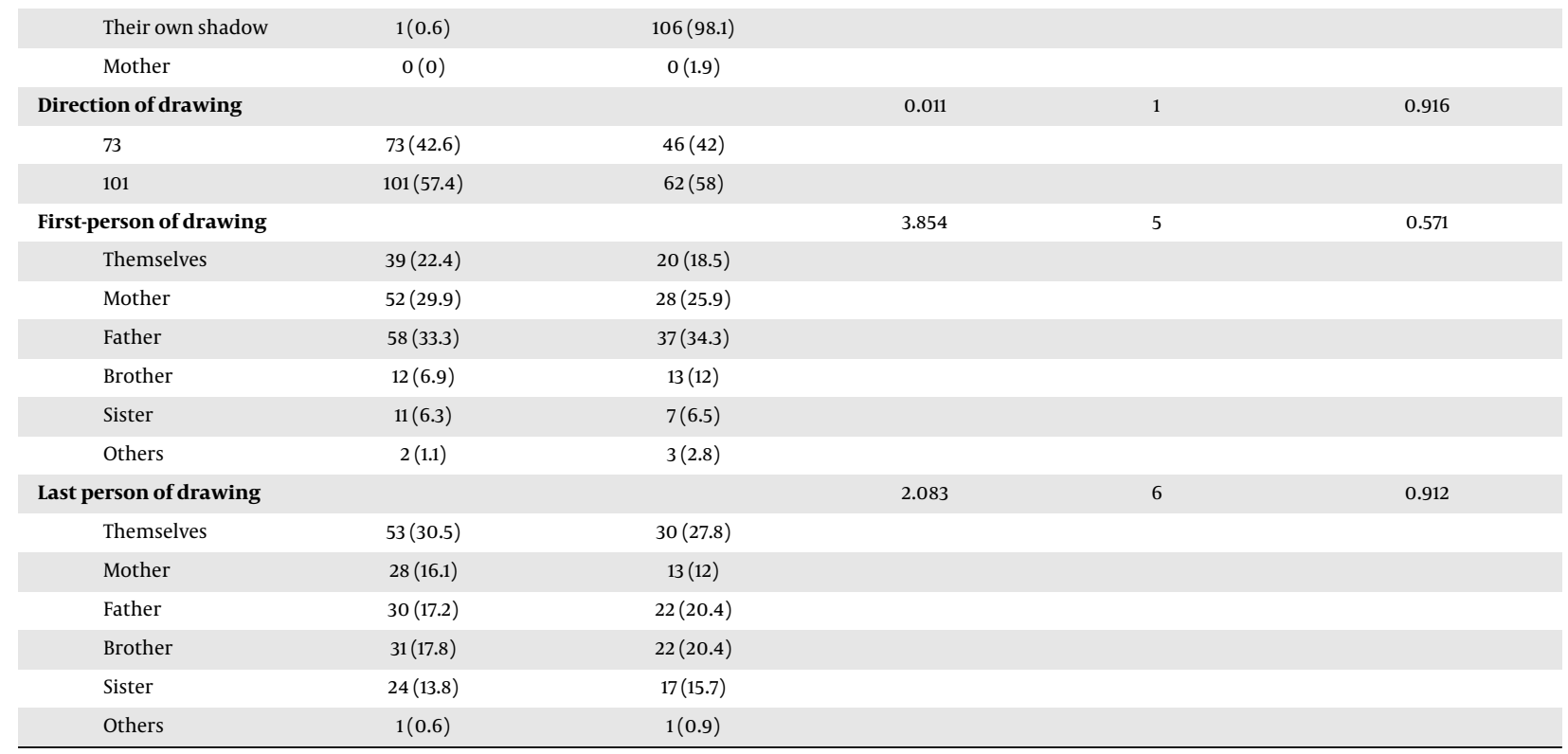

${ }^{\mathrm{a}}$ Values are expressed as No. (\%)

${ }^{\mathrm{b}}$ Significant level $<0.05$. 